\title{
SEVILLA: "PUZZLE" DE \\ DIVISIONES TERRITORIALES
}

Antonio MARTIN GARCIA*

\section{INTRODUCCION}

Si bien, prioritaria y secularmente, la Geografía, como ciencia del espacio, se ha ocupado en sus análisis territoriales de escalas supraurbanas, el desarrollo reciente alcanzado por el sistema de ciudades como lugar de concentración de la población, la actividad económica y el poder decisional, estan influyendo, de forma positiva, para que la atención se equilibre en favor de lo local.

Hasta fechas muy inmediatas, la diferenciación física y social de las partes de la ciudad era entendida sólo como un problema de límites resuelto con un nuevo trazado material de líneas. La urbe se concebía como un sistema unitario, homogéneo, estático... troceable según funciones.

Lo local, la ciudad, aprehendida como conjunto diferenciado de las partes, heterogénea física y socialmente, dinámica y cambiante, lugar de convivencia de ciudadanos, debe ser una ciudad donde la definición y adecuación permanente de las escalas territoriales submunicipales a las funciones socio-urbanas se convierta en principal garantía de su desarrollo.

Tras una exposición detallada de las diversas divisiones territoriales administrativas y sectoriales realizadas hasta hoy en el municipio hispalense, abordaremos el análisis de lo que constituye la demanda para resolver el "puzzle" de divisiones vigente y dejar planteado los imperativos para una territorialización o descentralización de los servicios y gestión diaria de la Ciudad.

\section{CLARIFICACION CONCEPTUAL}

Antes de definir los conceptos y delimitar los elementos constitutivos de organización territorial de la ciudad, es necesario algunas aclaraciones:

(*) Geógrafo. Gerencia Municipal de Urbanismo de Sevilla. 
a) Vamos a hablar siempre de divisiones territoriales oficiales, es decir, aprobadas por institución u organismo público.

b) Se expondrán divisiones territoriales que hayan incidido y delimiten hoy los ámbitos espacio-funcionales de la Ciudad.

c) Haremos referencia no sólo a las divisiones político-administrativas (distritos) sino también a las socio-urbanas (barrios y/o barriadas) y algunas de las sectoriales (consumo, sanitarias, ...).

Como concepto global, entendemos por división territorial urbana la delimitación tecnocrática de zonas o áreas, carente de análisis sobre la constitución del tejido residencial o conformación de los espacios, obviando las relaciones socioeconómicas de base diaria existentes y con fines administrativos, censales o electorales. Por oposición, definimos la ordenación física del territorio municipal como el proceso de configuración de espacios o áreas significativas y funcionales mediante la incorporación de las anteriroes variables omitidas, con participación ciudadana y teniendo como objetivo una óptima localización y racional gestión de los servicios y recursos públicos.

La organización territorial de la Ciudad ha estado apoyada, secularmente, en el distrito como compartimento administrativo y de representación política. Junto a él, se han efectuado diversas divisiones sectoriales, producto de las necesidades operativas de otras tantas áreas o servicios públicos locales, regionales o centrales. Sin embargo, la célula básica —el barrio y/o barriada-integradora de la vida social y cultural, con personalidad propia y formante del distrito, no ha sido definida física ni jurídicamente para permitir su incorporación al proceso de decisión y gestión de la Ciudad.

\section{DIVISIONES TERRITORIALES DEL MUNICIPIO DE SEVILLA}

\subsection{Las divisiones de distritos}

El término municipal de Sevilla se divide en distritos, por primera vez, en el aũo 1863. La división se hizo en diez distritos, basándose en ella el Empadronamiento de los habitantes, el Censo Electoral, las funciones de la Policía Municipal, la Recaudación de Impuestos y la Vigilancia, ... Emglobaba pués, aspectos administrativos y sectoriales. En cambio, aquellos distritos no formaban zonas o áreas unitarias continuadas (ver mapa $n .^{\circ} 1$ ) sino que como ocurría con el $3 .^{\circ}$ y $4 .^{\circ}$ (que componían el arrabal de Triana) tenían incrustado buena parte de su territorio fuera de los límites del barrio, en el Casco Antiguo de la Ciudad. 


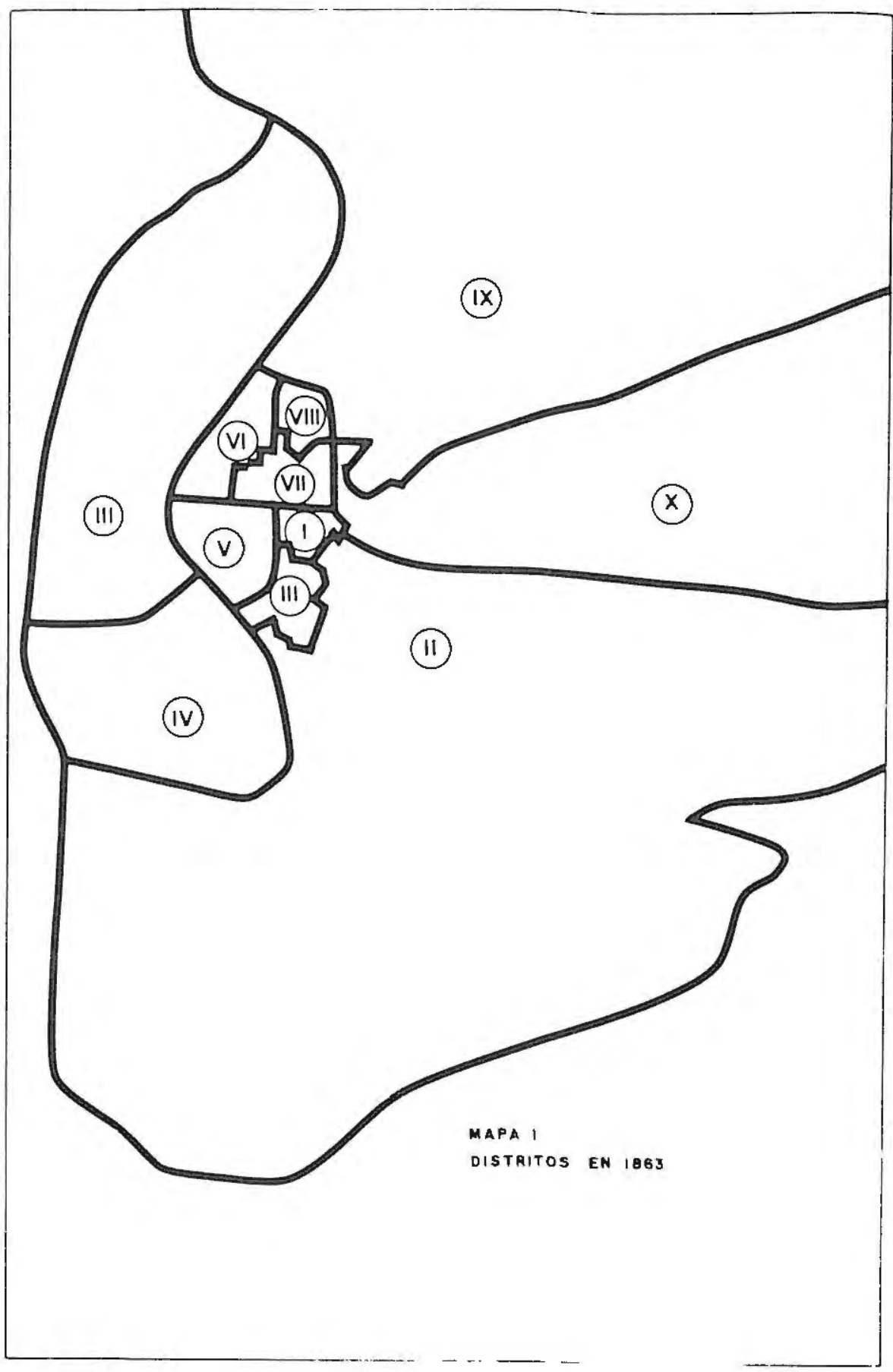


La siguiente división territorial de Sevilla se acomete por encargo de la Alcaldía a través del decreto de fecha 13 de Septiembre de 1967. Habían transcurrido más de diez décadas desde la última modificación territorial y la Ciudad dejó de ser un espacio residencial intramuros con pequeños arrabales exteriores (Cesteria, Humeros, Carretería, San Bernardo, Macarena y Triana). Se había convertido en la Sevilla de la periferia a raíz de la afluencia de emigrantes y el "boom" del sector de la construcción. Es la Ciudad reciente llena, a su vez, de permanencias físicas y culturales.

Los motivos que sustentaban la revisión de los límites de los distritos del siglo XIX eran los siguientes:

a) La discontinuidad de sus límites.

b) Las notables diferencias poblacionales interdistritos.

c) Conseguir una distribución más racional y operativa de Ios servicios públicos.

El procedimiento jurídico para materializar la revisión estuvo basado en el contenido de los artículos 121 de la Ley de Régimen Local y $3 .^{\circ}$ del Reglamento de Población y Demarcación Territorial de las Entidades Locales de 1955. Por acuerdo del Pleno Municipal de 28 de Febrero de 1968 y por el Ministerio de la Gobernación el 4 de Julio de 1970 se aprueba la delimitación de los vigentes distritos (ver mapa n. ${ }^{\circ}$ ).

El asesoramiento técnico para llevarlo a cabo había sido, exclusivamente, un informe de la Sección Municipal de Estadística sobre distribución de la población y sus límites, apoyados en los grandes ejes infraestructurales de la Ciudad (principales arterias viarias, el ferrocarril y el río) se establecieron tecnocráticamente y obviando los barrios naturales o históricos, el análisis urbano o las relaciones de base diaria existente.

Junto a una redefinición de los límites de los distritos, el decreto de la Alcaldía de 1967 contenía un segundo aspecto igualmente importante: reglamentar los cauces de representación y participación ciudadana en la vida local. Para ello se crearon las siguientes figuras legales ${ }^{1}$ :

1. Para un desarrollo del contenido político de las figuras creadas véase: A. Martín García. "Divisiones Territoriales básicas y primarias en la Ciudad de Sevilla: condiciones para una ordenación funcional de su espacio urbano", Ciudad y Territorio, n. ${ }^{\circ} 2 / 86$. 


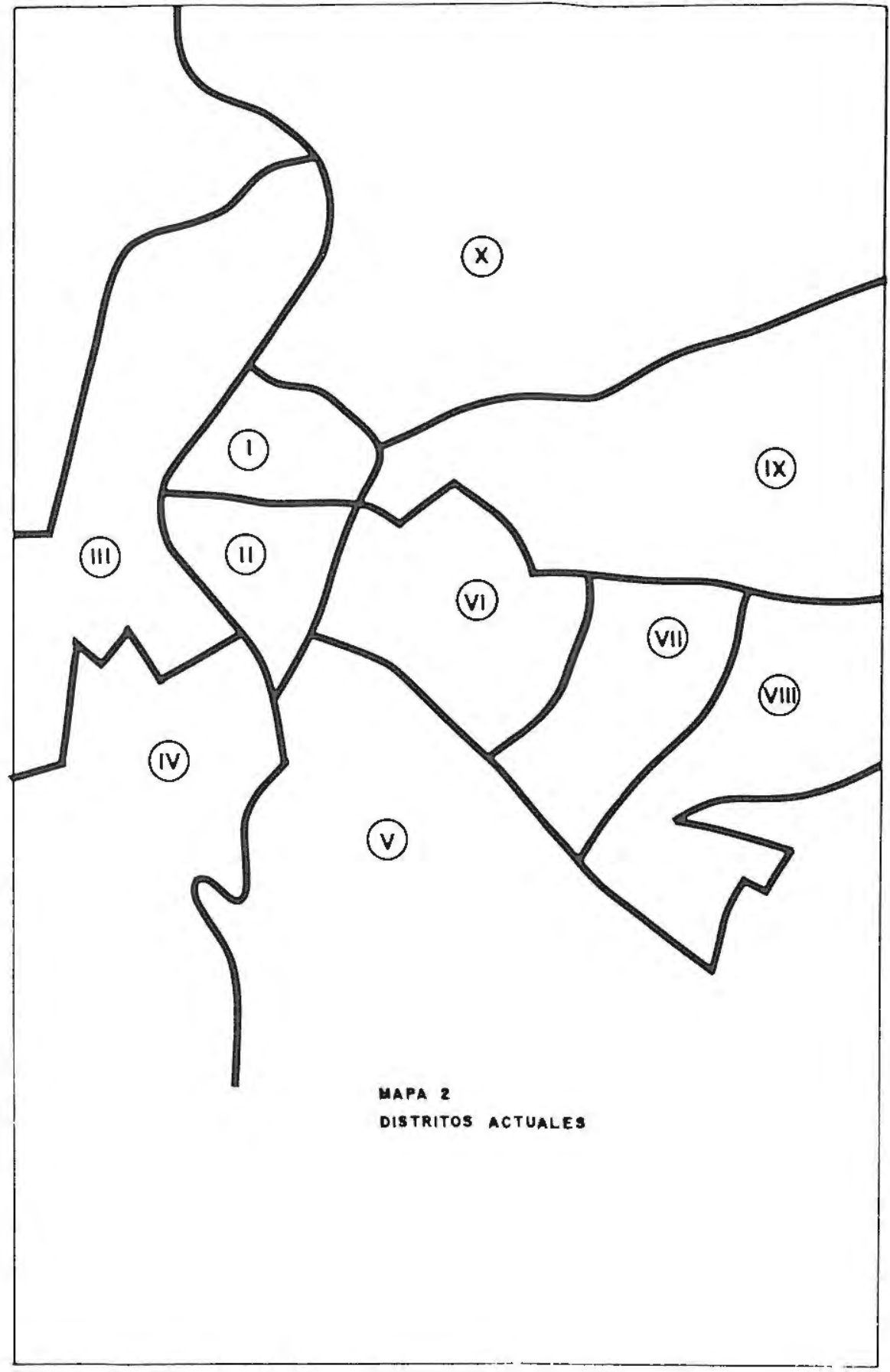


1..$^{\circ}$ Delegados de Distritos.

2. ) Alcaldes de Barrios.

3. ${ }^{\circ}$ Juntas de Delegados.

$4 .^{\circ}$ ) Colaboración de los ciudadanos con los Concejales de Distritos.

5. ) Oficinas Municipales de Distritos.

Además de los distritos municipales administrativos coexisten los distritos de Correos, Hacienda... que también han ido modificándose en el tiempo, pero que obviaremos en este artículo para no resultar agotador.

\subsection{Divisiones de barrios y barriadas}

En Sevilla sólo se ha acometido un proyecto de delimitación de la Ciudad en barrios. Se trata de una propuesta de la Alcaldía al Excmo. Ayuntamiento Pleno de fecha 23 de Febrero de 1971 una vez materializada la nueva división en distritos. El proyecto se caracterizó por los siguientes extremos:

a) Se trata de una división en barrios de los distritos. Esto es, se mantienen intactos los límites de estos aunque dividan a las unidades menores, llegando a formar, algunos de ellos, parte de dos o más distritos (ver mapa n. 3$)$.

b) Fue una compartimentación grosera, sin apoyo técnico-científico, con nula participación ciudadana y con objeto de imponer un determinado modelo político-administrativo.

c) La división arrojó 71 unidades menores o barrios. Configuró distritos con un sólo barrio (el cuarto: Los Remedios y el octavo: Torreblanca de los Caños) mientras que dividió a otros en un gran abanico de ellos (11 para los distritos quinto y sexto y 15 para el décimo).

No obstante, esta división nunca llegó a tener incidencia real en la Ciudad. No se utilizó como órgano de participación pública ni como ámbito de organización de los servicios municipales. Sólo tuvo un carácter simbólico o testimonial, materialzado a nivel de proyecto. El barrio como figura jurídica, con límites propios definidos y órgano emergente a considerar para la administración de la urbe, no ha existido aún en Sevilla. 


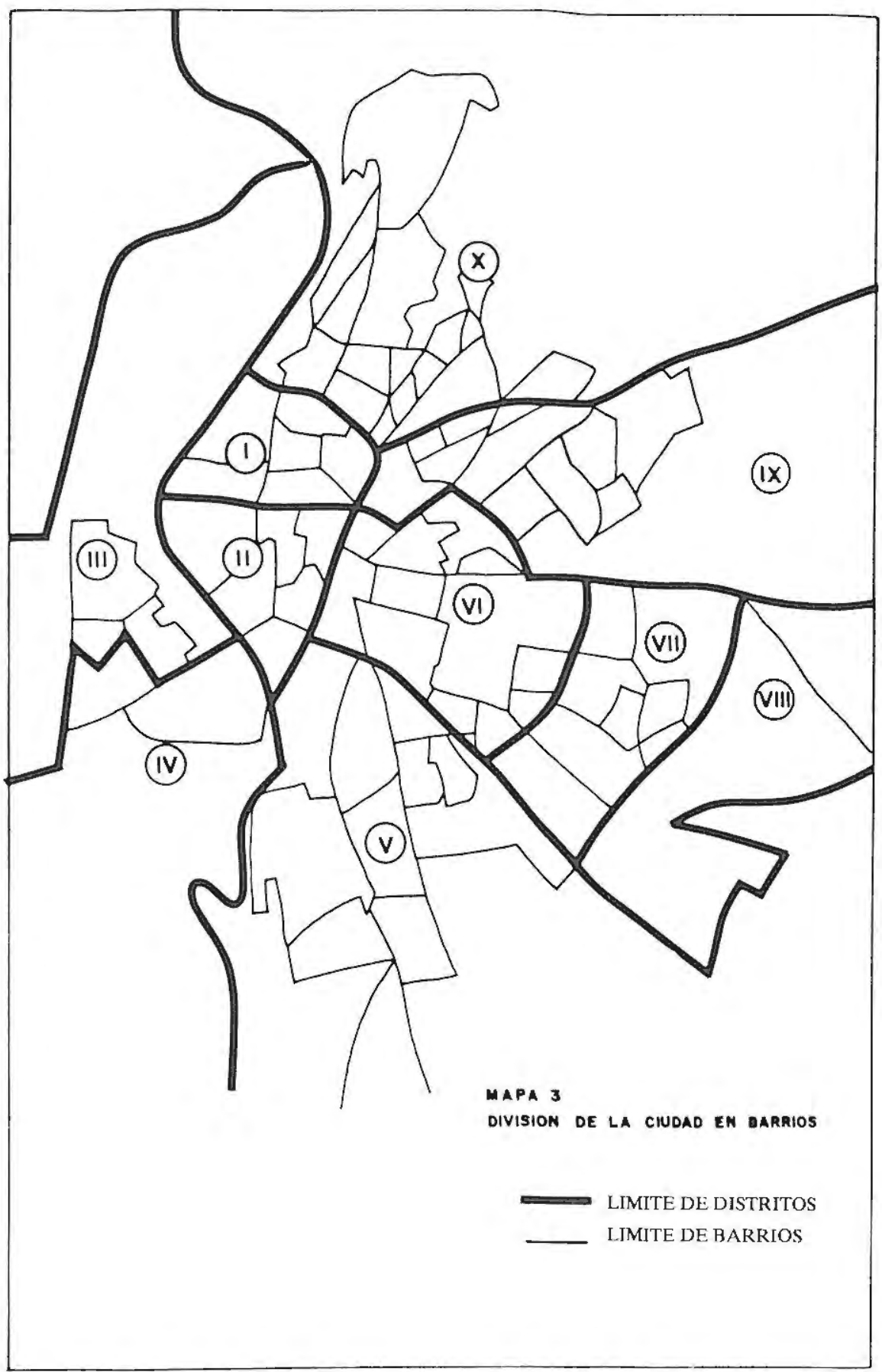


Junto a la anterior división, existió otro intento de subdivisión de las unidades menores en barriadas. La idea ni siquiera llegó a presentación de proyecto, sólo se quedó en boceto de plano, realizado a mediados de la década de los años cuarenta. En este plano se llegó a dividir a la Ciudad en 33 barriadas (ver mapa n. ${ }^{\circ}$ 4). Además, era una división parcial toda vez que sólo afectaba a las barriadas "extramuros" de Sevilla.

\subsection{Divisiones sectoriales}

Recopilar y desarrollar todas y cada una de las divisiones sectoriales realizadas, y vigentes, por las diversas Areas o Servicios Administrativos del Ayuntamiento, sería una labor excesiva para recogerlas en un artículo, teniendo en cuenta, además, que es necesario considerar también las divisiones efectuadas por las administraciones de ámbito supralocal que están incidiendo en la gestión de la Ciudad. Ante ello, hemos optado por incorporar sólo dos ejemplos de las numerosas compartimentaciones en curso. (Ver mapas n. ${ }^{\circ} 5$ y 6 ).

Si vamos, en cambio, a señalar algunos de los aspectos que caracterizan a estas divisiones:

a) Se trata de divisiones territoriales con un ámbito espacial superior al distrito y, por ende, aglutinadores de un abanico de barrios diversos.

b) Como consecuencia del punto anterior, sus límites rompen tanto las unidades administrativas como las asociativas y culturales.

c) Ninguna de las divisiones, de las que tenemos infomación, son coincidentes ni en el número ni en el tamaño de las escalas resultantes.

d) Son pués divisiones autónomas de cada Servicio, que responden a criterios funcionales de organización interna y sirven, a su vez, para aumentar la confusión en los ciudadanos y en los procesos administrativos ¿cómo se puede planificar o prever la gestión de las diversas Areas o Servicios con ámbitos espaciales tan dispares y dependientes de los distritos administrativos? Tan solo de una manera: yendo cada uno a su aire y restando eficacia en la gestión de la Ciudad. 


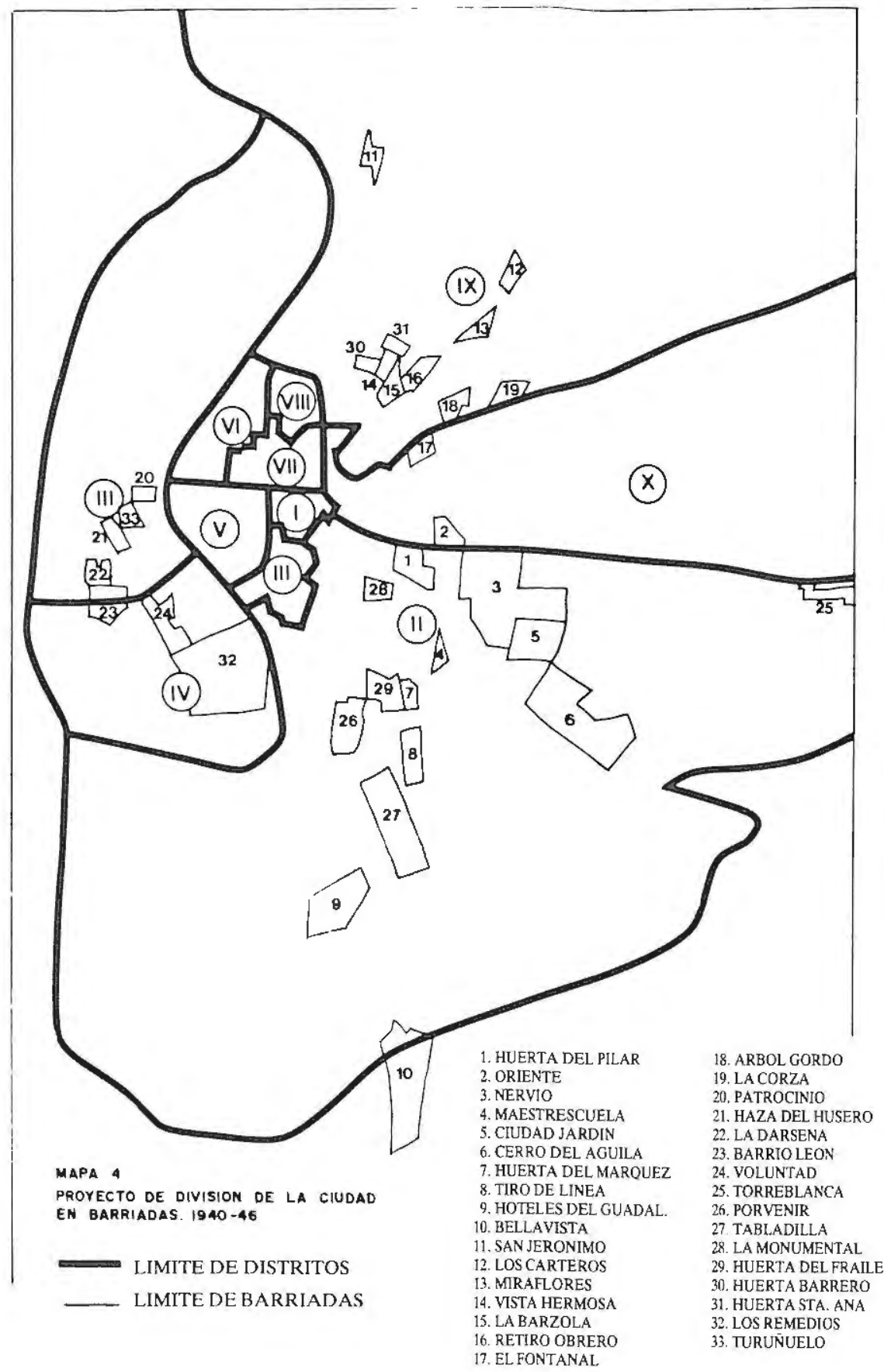




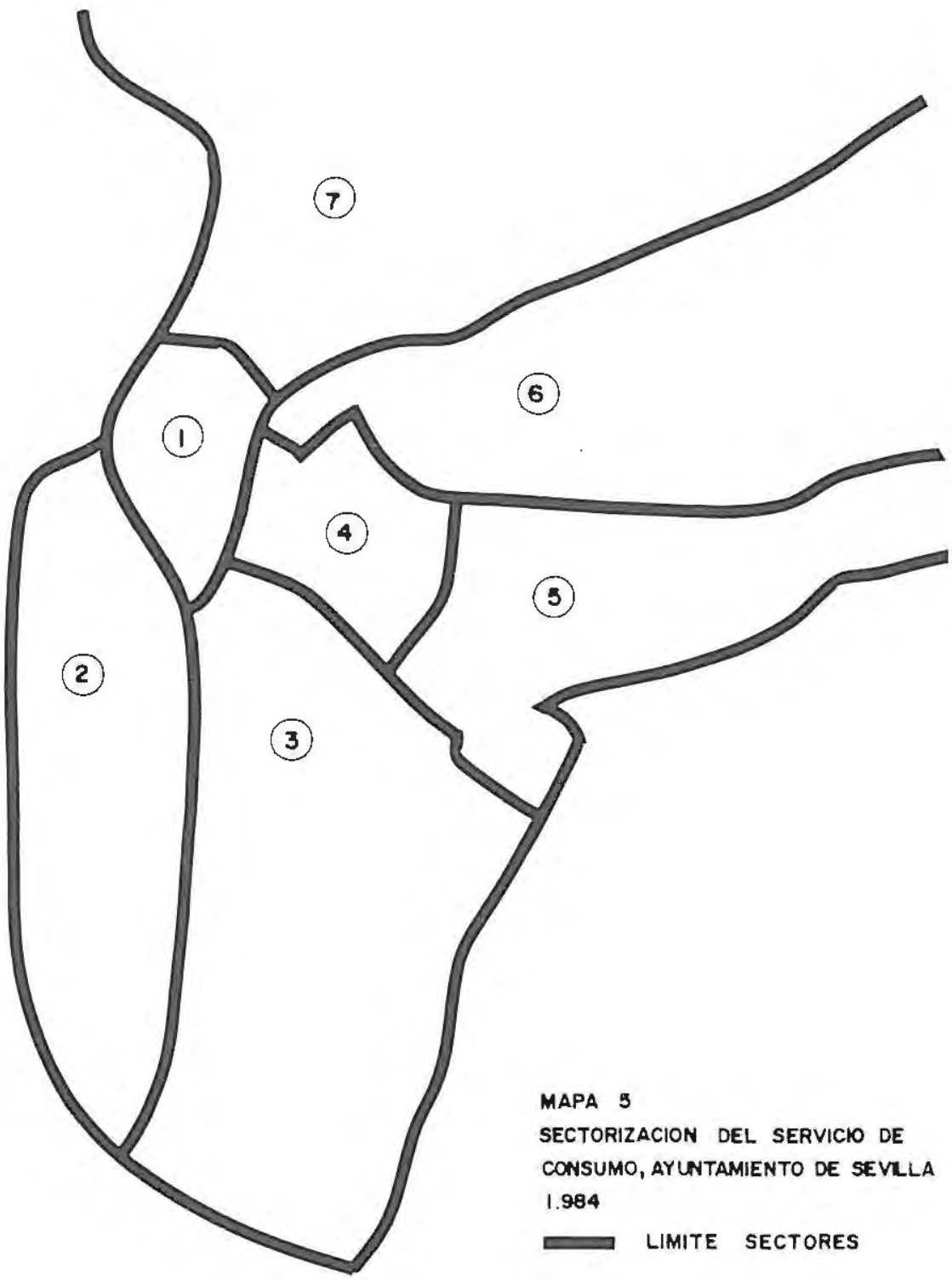




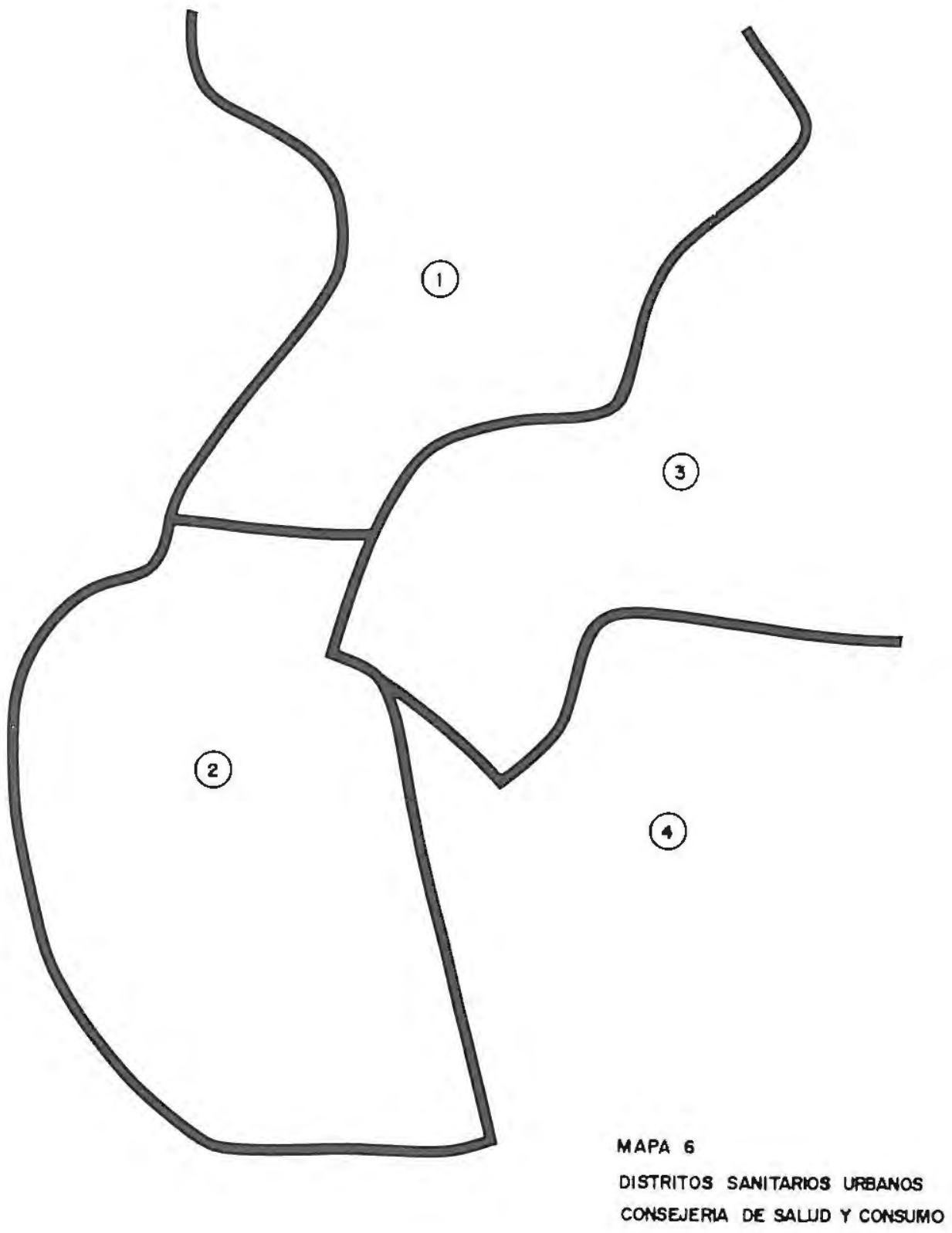




\section{DEMANDAS DE UNA ORDENACION FISICA-FUNCIONAL DEL ESPACIO URBANO HISPALENSE}

La necesidad de acometer la ordenación física-funcional de Sevilla viene siendo demandada desde dos ámbitos espaciales diferentes:
A) Ambito Metropolitano.
B) Ambito Urbano.

En este caso, nos vamos a centrar, exclusivamente, en exponer las consideraeiones de la demanda desde el ámbito local o urbano:

1.') La división en distritos de 1968 fragmenta barrios y/o barriadas históricas o naturales.

$\left.2 .^{\circ}\right)$ La falta de reconocimiento administrativo, jurídico y de entidad sociocultural propia de las unidades menores (barrios) de la Ciudad.

$\left.3^{\circ}{ }^{\circ}\right)$ Necesidad de homogeneizar los distritos municipales con los utilizados para servicios de la Adminsitración Central o Autonómica (Correos, Hacienda, Justicia...).

$\left.4 .^{\circ}\right)$ Los actuales distritos presentan desproporciones de población resideente y de superficie (ver cuadro $n,{ }^{\circ} 1$ ). Este notable desequilibrio viene a dificultar, aún más, la integración social y territorial de la población ${ }^{2}$.

5.) Sintetizar las diversas divisiones de la Ciudad de las Areas o Servicios Administrativos y coordinarlas con los espacios de los distritos, toda vez que éste es el ámbito de información poblacional y urbana.

$6^{\circ}$ ) Aumentar la racionalidad operativa y funcional en la prestación de los Servicios Municipales.

2. A. Martín García: "Divisiones territoriales...", Ciudad y Territorio, n. ${ }^{\circ} 2 / 86$. 


\section{CUADRO I}

SUPERFICIE Y EVOLUCION DE LA POBLACION DE LOS DISTRITOS DE SEVILLA (1960-1986)

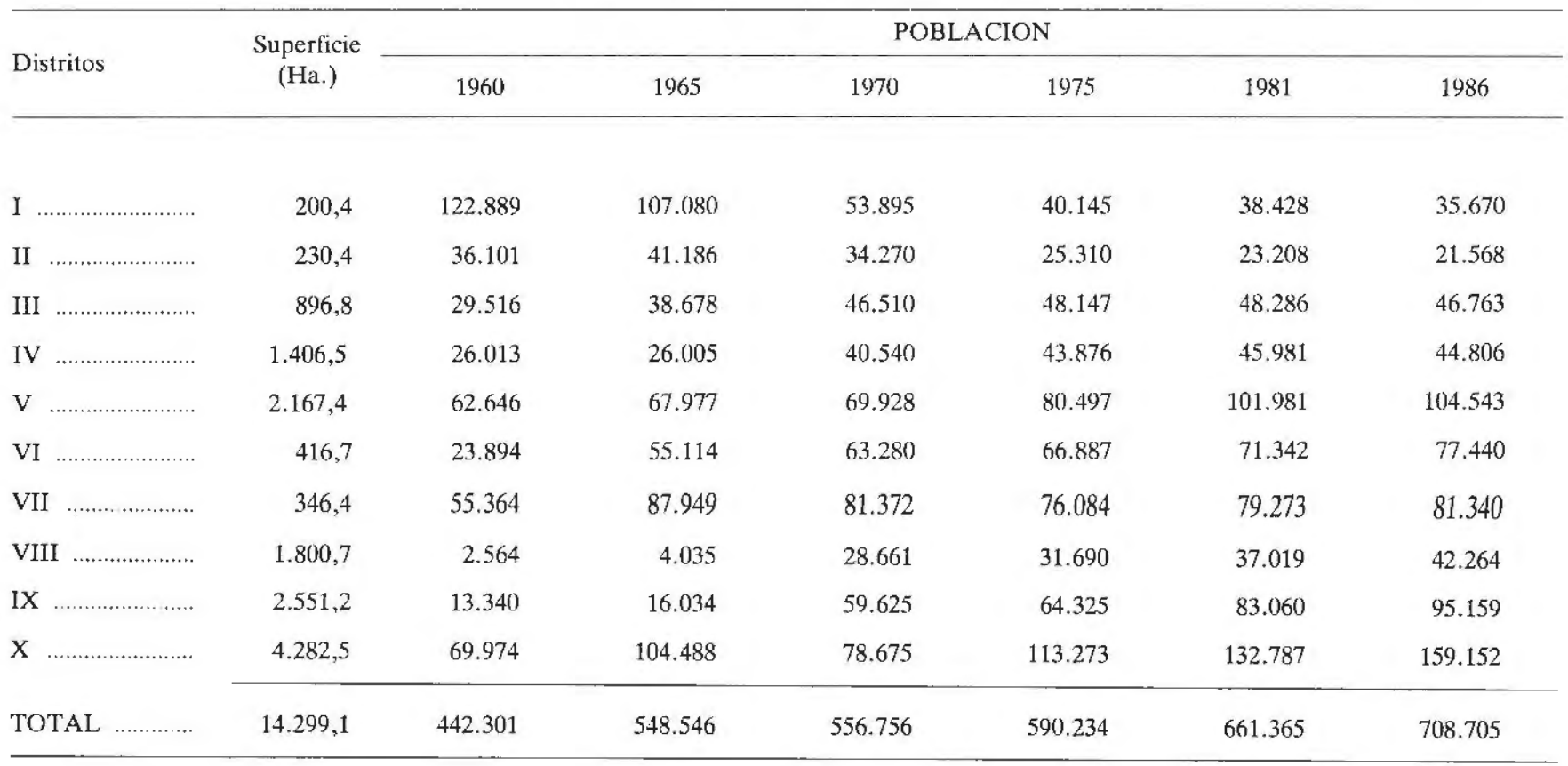

Fuente: Censos y Padrones de Habitantes. 


\section{5. ¿TERRITORIALIZAR O DESCENTRALIZAR?}

El aspecto más determinante de cualquier nueva propuesta para la organización territorial del municipio hispalense es el conocimiento de su formación espacial. Si se llega a saber de qué form a se organiza y funciona el sistema urbano se podrá dar un paso metodológico que coincidirá con el conocimiento geográfico (territorial) y social del espacio local.

Entendemos, pués, que el análisis territorial ha de conseguir los siguientes objetivos:

a) Entender las relaciones entre la realidad física y humana de la Sevilla actual (ciudad y metrópoli).

b) Conseguir unidades territoriales, doblemente significativas:

b.1) En primer lugar, respecto a las relaciones existentes y a las unidades de vida comunitaria.

b.2) En segundo término, desde el punto de vista de la organización y la eficacia administrativa.

c) Delimitar las unidades espaciales menores, naturales e históricas, a través de las relaciones humanas, identidad espacio-cultural y sentido e intensidad de las conectividades entre barrios.

d) Configurar distritos en base a las agrupaciones de barrios y de acuerdo con criterios de proximidad geográfica y condiciones socio-económicas.

Si bien nuestra hipótesis de partida es que se necesita una escala territorial semejante (número y dimensión de las unidades) tanto si se quiere descentralizar la administración local, como si sólo se quiere territorializar, manteniendo la organización centralizada actual, la diferencia entre ambas posiciones estriba en que la primera necesita de una voluntad política de actuación mientras que la segunda es suficiente con una voluntad técnica que tenga por objeto la racionalización de los servicios públicos.

Dentro de la etapa de elección democrática de las Corporaciones Locales -a partir de 1979- la ordenación físico-funcional de la Ciudad de Sevilla se ha obviado, hasta hoy, tanto a nivel básico (distritos) como primario (barrios y/o barriadas). 
Por otra parte, la voluntad política de descentralizar y potenciar la participación ciudadana en la gestión de los servicios públicos ha estado ausente en el Ayuntamiento hispalense desde 1979 a 1986. Aunque ello no ha imposibilitado la creación, con fecha de 27 de Junio de 1981 de Ias diez Juntas Municipales de Distritos en las que se divide Sevilla, la falta de competencias reales, su nula potenciación para que puedan influir en las decisiones municipales así como la precariedad de infraestructura y personal, ha facilitado el que se diluya la esperanza que a nivel ciudadano representó el slogan de la campaña del nuevo modelo de participación: "El Ayuntamiento más cerca". Entendemos que se ha recorrido el proceso de forma inversa, esto es, crear las Juntas Munieipales sin que se les haya permitido cumplir los objetivos programáticos que la conforman. A nivel de competencias es necesario conseguir, como señala Sánchez Morón, que: "la acción de la Junta o Consejo de Distrito ha de articualrse con la del Ayuntamiento a través de un doble mecanismo: consulta previa a la decisión y control de la ejecución" 3 .

3. Sánchez Morón: "Participación ciudadana y descentralización urbana: consideraciones básicas" CEUMT. La Revista Municipal, n. ${ }^{\circ}$ 25-26, pp. 21-27. 